\title{
HET MERKWAARDIGE WARAU
}

DOOR

C. H. DE GOEJE

Zoo ver de overlevering en de geschreven geschiedenis teruggaan, wonen de Warau-Indianen, ten getale van vele duizenden, in en om de delta van de Orinoco, en hier en daar in de kuststreken van het tegenwoordige Britsch Guyana en het Westen van Suriname.

Met hun taal maakte ik kennis, toen mij voor meer dan twintig jaar bij het verzamelen van literatuur over de talen,van Guyana, in handen kwam het boekje „Questions on the Apostle's Creed with other simple instruction for the Warau Indians at the Missions in Guiana.'

In vrije oogenblikken heb ik getracht uit de 13 bladzijden Warau-tekst van dat boekje eenige taalregels te voorschijn te halen, doch dit werk bleef, toen ik kort daarop naar Oost-Indië ging, liggen, en ik heb het eerst weder opgevat op de reis met Hr. Ms. „Hertog Hendrik” naar West-Indië in 1927/28. Het schip zou namelijk Suriname aandoen, en ik wilde voorbereid zijn om bij eene eventueele ontmoeting met Waraus, mijne vragen over hun taal goed te kunnen stellen.

Nochtans was de kans op een dergelijke ontmoeting al heel gering, want slechts 15 dagen zouden wij te Paramaribo blijven, en de weinige Waraus in Suriname wonen heelemaal in het Westen der kolonie. Er zou dan ook wel niets van gekomen zijn, als niet op het uitstapje van de drie oud-expeditieleiders: Stahel, Käyser en ik, naar Gansee, het gesprek was beland op deze zaak. - Stahel ziet een mogelijkheid, en zoodra de tram te Kabelstation aan- 
komt, telefoneert hij. Er wordt geseind naar Nickerie, en daar is men niet minder voortvarend. Het gevolg is, dat ik eenige dagen later in Stahels gastvrije woning zit tegenover twee echte Waraus, gekomen van Wasiabo aan den Corantijn: Philip Samuel en Charles Aban.

Beiden zijn op een Engelsche missie-school (?) geweest, en verstaan Engelsch; Samuel spreekt en schrijft het zelfs vrij goed.

De gewilligheid der Waraus is groot; alleen: na een paar uur vragen worden ze vermoeid. Dan gaan wij ons verpoozen op het balkon, kijken naar de wolken, naar de stroomende rivier, naar de krabben die bij laag water over de modder rennen, en dat geeft aanleiding tot weer nieuwe vragen. Als dan hun aandacht volkomen, en hopeloos, verflauwt, krijgen zij rust, en vervolg ik Arawaksch met Baptist.

- Veel te spoedig is de dag van het vertrek er. Afscheid van deze trouwe vrienden, en naar boord. - Iets later begint het aan den waterkant vol te stroomen van menschen, en terwijl het schip het anker licht en langzaam onder stoom gaat, onder hoera's van den wal en van boord, kijk ik door de binocle naar het huis van Stahel: en daar op het balkon staan naast hem de Indianen, vriendelijk wuivend.

Even later verdwijnt Paramaribo achter den hoek, en met zonsondergang passeeren wij het lichtschip en begint de oversteek naar de Kaap Verden. Amerika ligt achter ons.

- Weemoedig is zoo'n afscheid altijd. Doch er is werkelijk geen tijd om daarover sentimenteel te worden. Een groote hoeveelheid Arawaksche gegevens moet worden uitgezocht, en gereedgemaakt voor inlassching in mijn reeds ingediend werk over die taal. Nadat dit alles gereed is - ik zit inmiddels alweer in mijn kamer in Den Haag - is er nog ander dringend werk, en zoo vergaan er vele maanden eer ik kan beginnen met uitzoeken van den Warau-oogst: een 1500 woorden en zinnen, de verklaring van eenige duistere vormen in de „Questions”, en twee mythen die Samuel mij opschreef, en die wij daarna gezamenlijk doorwerkten. 
Dan komen de verrassingen:

In October kom ik te Parijs en bespreek de publicatie van mijn Warau-materiaal met Dr. Rivet, den secretaris der Société des Américanistes de Paris. En daar verneem $\mathrm{ik}$, dat in het tijdschrift van het genootschap een uitvoerig artikel over de Waraus en hun taal zal verschijnen, van de hand van den Reverend James Williams. Het blijkt een uitmuntende samenvatting te zijn van al wat door verschillende onderzoekers is opgeteekend, en ook taalmateriaal te bevatten dat tot dusver niet gepubliceerd is geworden. Bovendien zie ik uit de toegevoegde literatuurlijst, dat de "Questions” reeds vroeger waren uitgeplozen door den beroemden Amerikanist Lucien Adam $\left.{ }^{1}\right)$.

Enkele maanden later meldt men mij dat zoo juist in Venezuela een Warau grammatica is verschenen, samengesteld door Pater B. Ma. de Olea, en vervolgens dat een Warau vocabularium uit de $18 \mathrm{e}$ eeuw, als manuscript aanwezig in de Koninklijke Bibliotheek te Madrid, is uitgegeven ${ }^{2}$ ).

En nog meer komt voor den dag. Lucien Adam, die de "Questions" voor de taalwetenschap had ontdekt, had dergelijke boekjes gevonden in het Karaïbisch en in het Arawaksch, en een veel uitgebreidere uitgave in het Akawoio. In Mei '29 te Londen zijnde, vind ik bij de Society for Promoting Christian Knowledge die uitgebreidere uitgave ook in het Karaïbisch, en als de Revd. James Williams mij zijn boekenverzameling toont, blijkt het dat hij dit werkje in het Arawaksch bezit. Wij meenen dat er nu ook wel een uitgebreidere uitgave in het Warau zal bestaan, en gaan beiden op zoek. In den boekwinkel der S.P.C.K. verzekert men mij dat het nooit bestaan heeft, en ook in de bibliotheek der British and Foreign Bible Society is het niet te vinden. W. heeft echter meer geluk,

\footnotetext{
1) Lucien Adam, Esquisse Grammaticale et Vocabulaire de la Langue Guaraouno. Congreso Internacional de Americanistas. Actas de la undécima Reunión (1895). Mexico 1897.

${ }^{2}$ ) Kort besproken in den W. I. Gids, 11e jaargang, 's Gravenhage 1929.
} 
„hoewel”, zoo schreef hij mij, ,geheel bij toeval, want de winkel-assistente zeide mij dat ze geen exemplaar hiervan hadden, en zulks nadat zij mij twee hunner boekjes had gegeven, een waarvan juist het Warau-boekje was waarvan zij had gezegd dat het niet aanwezig was!'” 1).

- Een jaar tevoren was er zoo weinig bekend van het Warau, dat mijn materiaal veel nieuws zou brengen.

$\mathrm{Nu}$ zal het nog slechts de moeite loonen om daarvan eenige taalregelen en woorden te publiceeren die bij andere schrijvers ontbreken, en daarbij de beide mythen met interlineaire vertaling, omdat tot dusver nog geen langere origineele Warau-teksten zijn opgeteekend.

Bij de bewerking zijn evenwel allerlei samenhangen ontdekt, die een blik gunnen in het diepere wezen van deze taal, en ook wat leeren omtrent de wereldbeschouwing van den Warau. Dat zal dezer dagen in druk verschijnen ${ }^{2}$ ); hier wil ik er een en ander van mededeelen in verhaaltrant.

Een nieuwe taal ligt in geschreven afgietsel voor mij. Welke geheimen liggen daarin verborgen?

De eerste indruk van het Warau is: een taal eenigszins gelijkend op het Karaïbisch en Arawaksch, doch met een geheel anderen woordenschat, en niet rijk aan vormen.

Dan probeer ik of in het Warau evenals in het Arawaksch, ${ }^{3}$ ) de verschillende klinkers en medeklinkers elk

1) Simple Questions on the historical part of the Holy Bible for the instruction of the Warau Indians at the Missions in Guiana. London, S.P.C.K., vermoedelijk omstreeks 1850 verschenen, en samengesteld door den zendeling W. H. Brett; $52 \mathrm{blz}$., waarvan de laatste 13 de "Questions on the Apostles' Creed" etc. zijn.

Een grammatica van het Warau is door wijlen W. H. Brett niet nagelaten, wel een vocabularium van 550 woorden, waarvan mij in 1908 welwillend inzage werd verleend door de familie Brett te Lougborough.

$\left.{ }^{2}\right)$ The inner structure of the Warau language of Guiana, by C.H.d. G., Journal de la Société des Américanistes de Paris, Nouv. Série, XXI Fasc. 2, Paris 1930.

s) Zie Het merkwaardige Arawaksch, door C. H. d. G., W. I. Gids, 11 e jaargang, 's Gravenhage 1929. 
een eigen beteekenis hebben, en rangschik daartoe de woordwortels en toevoegsels naar hun klanken. En waarlijk! daar is lijn in te bespeuren: en gaandeweg wordt het duidelijk dat de meeste woorden geheel, of voor een deel, te verklaren zijn uit een bepaalde beteekenis der klanken, die ik hier laat volgen. Regelrechte tegenspraken zijn niet gevonden.

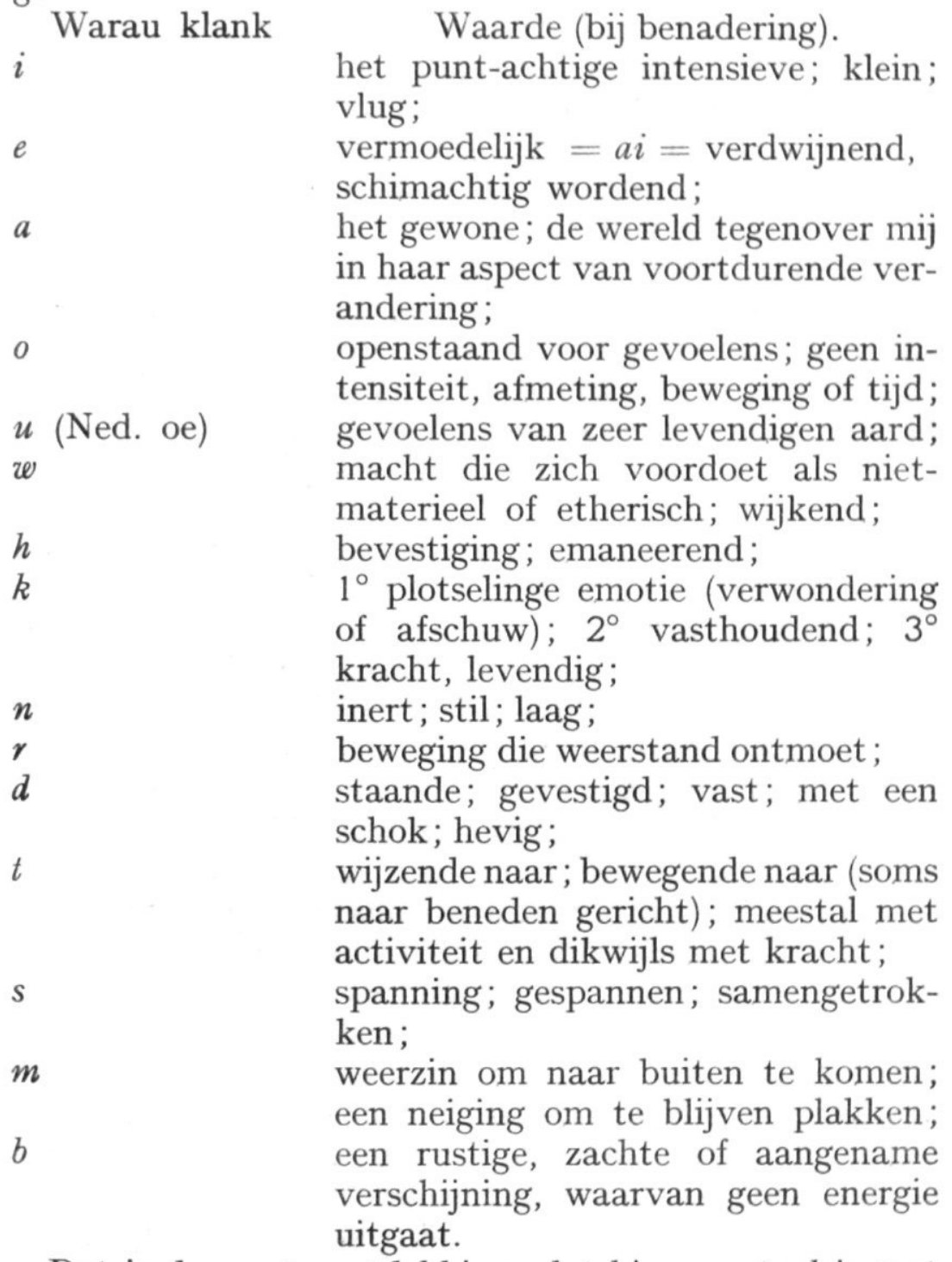

Dat is de eerste ontdekking: dat hier een taal is met 
geheel eigen woordenschat, waarvan de woorden grootendeels of geheel klanksymbolen zijn, en dat de beteekenis der enkele klanken in die woorden, in groote trekken dezelfde is als reeds in andere talen werd gevonden.

- Hoe komt de mensch ertoe, zich uit te drukken in deze oerelementen?

- Ik herinner mij een tooneelstuk, naar ik meen van Fabricius, waarin een der personen, een Indo-Europeaan met sterk emotioneel karakter, een jacht beschrijft, en daarbij onwillekeurig het gebaar maakt, hoe hij schiet. Een bepaalde zieleroering werd daar tot het gebaar dat paste bij die zieleroering, dat er als het ware de projectie in ruimte en tijd van was.

Dat moet ook de oorsprong zijn van deze spraakklanken, die immers eveneens een soort gebaren zijn: gebaren van de spraakorganen, van de andere gebaren zich slechts onderscheidend doordien ze grootendeels onzichtbaar blijven, maar hoorbaar zijn.

Bij de allereenvoudigste reflexbewegingen, zooals het reageeren op een schrik, is elke snelle beweging van de spraakorganen passend, en wij moeten ons dan ook niet verwonderen als we in één taal $k a$ !, in een andere $m a$ ! aantreffen als uitroep van schrik of plotselinge verwondering. Zoodra er echter in de zieleroering iets meer specifieks is, een bepááld gevoel, een bepáálde wilsstoot (idee die naar buiten dringt), dan wordt een keuze gedaan uit de verschillende gebaren der spraakorganen die mogelijk zijn. Die keuze geschiedt instinctief, en toch volgens een bepaald stelsel, dat naar ik vermoed, oer-menschelijk zal blijken te zijn, in de menschelijke natuur ligt.

Het verband tusschen een bepaalde zieleroering en de daarbij behoorende spanning, beweging of vorm der spraakorganen kunnen wij aan onszelve vrij goed nagaan. Bijvoorbeeld wordt het gevoel: willig en instaat om te bewegen, vrije beweging, uitgedrukt door de (in het Warau ontbrekende) $l$ : de punt der tong snelt naar voren. Het gevoel: willende bewegen, maar daartoe niet instaat; beweging die belemmerd wordt, enz., wordt uitgedrukt door de $r$ : de punt der tong maakt een achterwaartsche 
beweging. Het gevoel: onbewegelijk, onverschillig, soms: verdrukking, door de $n$ : de punt der tong ligt onbewegelijk en vlak tegen het harde verhemelte of de tanden.

En daar het zielegebeuren, als dat ontstaan is uit waarneming van een ding of gebeuren in de buitenwereld, hiermede verbonden is, behoeft het ons niet te verwonderen dat het gebaar der spraakorganen soms een zwakke gelijkenis toont met het ding of gebeuren, er als het ware een vernieuwde schepping van is ${ }^{\mathbf{1}}$ ). Zoo'n gelijkenis is er bijv. tusschen het $n$-spraakgebaar (tong vlak en onbewegelijk tegen hard verhemelte of tanden) en den vlakken onbewegelijken aardbodem: Arawaksch ona-bo, laag, de grond, Karaïbisch nono, de grond, Warau no-ika, onder; misschien mogen ook daarbij worden gerekend de Nederlandsche woorden onder en grond. ${ }^{2}$ ) Enz.

- Nu kunnen wij innerlijk waarnemen, dat ons geheele zijn en doen van twee zijden uit bestuurd wordt. De eene zijde is die van ons zelfbewuste wilswezen, onze zelfstandige ik-kern. De andere zijde is die van het lichaam, of algemeener uitgedrukt, van de menschelijke natuur, door welke ook de buitenwereld, de groote natuur, met ons verbonden is.

Zonder twijfel is de hier besproken klanksymboliek voortgekomen uit de natuur, en lang geleden kan dat niet zijn, want hoewel woordwortels en voor- en achtervoegsels zich gestabiliseerd hebben, toonen ze hun herkomst nog zeer duidelijk.

Aan de taal is nu bovendien te bemerken, dat bij den Warau het besef van de tegenstelling tusschen ik en nietik of tusschen persoon en ding, minder sterk, of anders, is dan bij ons.

\footnotetext{
1) Voor de hier gevolgde beschouwingswijze is deze ruimtelijke gelijkenis in vorm en beweging niet essentieel. Een ander onderzoeker, Sir Richard A. S. Paget, Bart., ziet in vele woorden van verschillende talen een regelrechte pantomime. Zie zijn opstellen The Origin of Speech - A Hypothesis. Proc. Royal Society, A, Vol. 119, London 1928, en Human Speech. Nature, Febr. 1929.

$\left.{ }^{2}\right)$ Zie: Over den oorsprong der klanken in het Nederlandsch, door C. H. d. G., Donum natalicium Schrijnen, Nijmegen 1929.
} 
HET MERKWAARDIGE WARAU

\section{III}

Die mededeeling mag wel wat nader worden toegelicht. Doch misschien zijn er onder de lezers, die uit hun schoolen examentijd een oude veete hebben tegen al wat naar grammatica riekt, en dezulken beveel ik aan om van dit hoofdstuk alleen het slot luchtigjes door te kijken.

- Laat ons uitgaan van een eenvoudig zinnetje: tai $m a-y e h e b u-y a=$ hij roept mij, lett. die mij-roep-end.

Al dadelijk valt op, dat de persoon die de handeling ondergaat, vóór de handeling wordt genoemd: dit is een vaste regel, en de le pers. enk., 2e pers enk. en le pers. mrv. worden alsdan aangeduid door een persoonsprefix dat niet zelfstandig kan worden gebezigd: $m a-$, $h i$ - en $k a-$. De volgende vormen wekken het vermoeden dat die persoonsprefixen niet aanduiden den persoon die de handeling ondergaat, doch de plaats waar de handeling eindigt: ma-rani ma-moa-i aru, mijne moeder gaf mij brood, lett. mij-moeder mij-gaf kassavebrood, arokobo sanuka ma$m o-u$ ! geef mij een weinig brood! lett. broodbol weinig mij -geven-nadruk, ine hi-moa-ya, ik geef het aan jou, lett. ik jou-gevend.

Maar dezelfde persoonsprefixen worden op dezelfde wijze gebezigd in vormen die niet een handeling aanduiden, zooals: ma-hanoko, mijn huis ,hi-hanoko, jouw huis, ma-kobe, mijn hart, ma-uka, mijn zoon, ma-kaika met mij (mij-met), ma-saba, voor mij, hi-kwari bij jou.

De eenige verklaring die ons tenslotte kan bevredigen, is dat de persoonsprefixen aanduiden „plaats”, d.w.z. een op bijzondere wijze aangevoelde plek in het wereldgebeuren.

In andere gevallen worden dezelfde personen aangeduid door ine, ihi en oko (of hine, hihi, hoko). Deze woordjes duiden aan den persoon van wien de handeling uitgaat, of die in een toestand verkeert, bijv. tatika ine aba-nai, ik heb het hier geplaatst, lett. hier ik geplaatst, ine waba$y a$, ik ben ziek, lett. ik ziekend. Doch zij worden op dezelfde wijze als bepalingen van plaats, tijd, omstandigheden enz., al naar er de nadruk op moet vallen vóór of 
achter het handeling- of toestandwoord uitgesproken, wat er ook al op duidt dat de persoon voor den Warau een omstandigheid is, een belangrijke omstandigheid zoo men wil, doch niet iets zoo primairs als hij voor ons is.

En nogmaals wijst daarop, dat de voornaamwoorden van den 3en persoon die op dezelfde wijze als ine, ihi en oko worden gebezigd, beduiden: tamaha = deze-hier, tai $=$ deze verderaf. De 3e persoon wordt echter dikwijls in het geheel niet genoemd, en een persoonsprefix van den 3en persoon bestaat zelfs niet.

Het is eigenlijk net andersom als bij ons: wij fantaseeren er een 3en persoon bij, als we er geen kunnen aanwijzen, en zeggen ",het regent”. De Warau laat den 3en persoon weg als die wel aanwijsbaar is, en zegt voor: hij slaat mij, ma-yewere-ya, mij-slaande, en voor: „hij heeft een vrouw gedood" tida-si na-ie, vrouw-scherpe nadruk gedood.

Dat wijst erop dat handelingen die wij voelen als uitstralingen van een persoon, door den Warau gevoeld worden als een onpersoonlijk natuurgebeuren (of ál-persoonlijk gebeuren).

Voor onze werkwoorden „hebben” en „zijn”, die zoo sterk verbonden zijn aan een persoons-gevoel, bezigt de Warau een onpersoonlijken vorm: $h a$ is er is, bijv. ik heb weinig geld, ine burata sanuka ha, lett. ik geld gering er-is; hier is veel klei, tamatika hoboto era ha, lett. hier klei veel er-is; God was goed jegens Abel, Kanonatu Abel sahba yakira-ha, lett. God Abel jegens goed er-is.

Bovendien is er een werkwoord ,bezitten" = oraba $=$ or $(i)$ zelf $(h) a b a$ blijven. Or $(i)$ beduidt echter $o$ niet veranderend $r(i)$ beweging die belemmering ontmoet.

Voor ons ,willen”, dat de persoonlijke kracht en activiteit zélve is, bezigt de Warau obono = liefhebben, wenschen, en hoewel de innerlijke beteekenis van dit woord niet met zekerheid is vastgesteld, wijzen zijn klanken en drie lettergrepen allesbehalve op een gevoel van kracht en activiteit. Ook is obonobu = denken, hieraan verwant.

Een onderscheid tusschen actief en passief werkwoord bestaat niet in het Warau; wel kan een intransitief werk- 
woord door voorvoeging van $i$ - of $y(e)$-transitief worden gemaakt, doch waarschijnlijk duidt dit niet anders aan dan dat de verhouding tot het tevoren genoemde, of het verzwegen object eene is van spanning, en duidt de bij het zelfstandig naamwoord voorgevoegde $a$ op een rustiger verhouding.

De volgorde in woorden en zinnen wijst erop, dat de Warau sterk emotioneel is, al blijft dit misschien, evenals bij andere Indianen, veelal verborgen achter uiterlijke kalmte. De normale volgorde is: 1 plaats of ding 2 eigenschap, toestand, verhouding of gebeuren; doch de volgorde kan ook omgekeerd worden als emoties in het spel komen, en vermoedelijk wordt alles tezamen gedekt door de formule: 1 emotie-uitdrukking; 2 bezinnings-uitdrukking. Een vorm als tobe simo, poema, zou dan ontstaan uit den kreet tobe !tijger! en de rustiger aanduiding simo, rood.

En verder vindt men bij het ontleden der woorden overal, dat de Warau zich op naief-eenvoudige wijze uitdrukt, levendig, beknopt, en duidelijk.

Eenige voorbeelden:

$i i=$ tand, kies $(i$ intens of klein $) ; h o b i=$ drinken of drank ( $h o$ water $b$ rustig $i$ even of een weinig); $n a=$ dooden of gedood worden ( $n$ onbewegelijk $a$ gewone realiteit); $n a k a=$ vallen $(n a$ onbewegelijk, naar beneden, $k a$ plotseling geschieden), nanaka = afdalen ( $n a-n a$ herhaald naar beneden $+k a) ; n a h a=$ regen ( $n a$ naar beneden $h a$ zijnde, of $a h a$ damp); $n a b a=$ een groot water ( $n a$ onbewegelijk of beneden $b a$ rustige verschijning) ; $n a b a=$ tapir (idem); $w a b a=$ ziek zijn, sterven $(w a$ wijkend, verdwijnend $b a$ rustig); (h)aba = plaatsen (eigenlijk :blijven; ha zijnde $b a$ rustig); $i a b a=$ verlaten (transitief blijven), $-s a h b a$, achterzetsel, bijv. Kanonatu (God) tatuma (deze, meervoud) sahba (tot) dibu-nae (sprak) = God sprak tot hen ( $s$ spanning, aandacht trekkend haba blijven); habata $=$ schrijven ( $h a b a$ blijven $t a$ aanbrengen); hata $=$ schieten (ha zijn of uitstooting $t a$ bewegend naar); hatabu $=$ pijl (hata schieten $b u$ levendige verschijning); hataburau = boog (hatabu pijl rau, dau hout, boom); kaba = hakken 
( $k a$ kracht, plotseling $b a$ rustig); $b a k a=$ lang en recht (ba rustig $k a$ sterk); dabodobaka $=$ speer (dabo mes $d o$ stoot baka lang en recht).

Het is alles onderstelling en kan hier en daar wel eens mis zijn, doch als geheel is het wel zeer waarschijnlijk juist.

Zoo gaat het de geheele taal door. Als regel hebben de woorden van het Warau niet het karakter van willekeurig gekozen en door onderlinge afspraak bevestigde teekens, die als etiketten op de verschillende dingen, gebeurtenissen enz. zijn geplakt, doch zijn ze een soort herhaling in spraakgebaren van het ding of gebeuren zelve. De beginselen die daarbuiten in de groote natuur zijn en werken, vinden een onmiddellijken weerklank in de menschennatuur. En de persoonlijkheid leeft daarin, is niet in die mate als bij ons, zelfstandig.

Iets van denzelfden aard als dit laatste, is door den hoogleeraar Uhlenbeck gevonden in verschillende andere talen, en hij heeft het vermoeden uitgesproken dat dit eigen is aan een zekere phase van geestesontwikkeling, die wij reeds achter den rug hebben. ${ }^{1}$ ).

- Het is daarom niet te gewaagd om aan te nemen dat de Waraus een ouder menschentype vertegenwoordigen dan wij; niet minderwaardig, doch meer dan wij één met de groote natuur, en minder dan wij zelfstandig geestelijk wezen.

De verschijnselen der taal wijzen erop, dat de Arawakken iets dichter bij ons staan dan de Waraus.

\footnotetext{
1) Het passieve karakter van het verbum transitivum of van het verbum actionis in talen van Noord-Amerika, door C. C. Uhlenbeck. Versl. en Med. Kon. Ak. v. Wet. afd. Lett. 5e reeks deel II, Amsterdam 1916.

Vgl. daarmede wat Prof. A. Meillet (Parijs) heeft gezegd over de volken der Indo-Europeesche taalfamilie op het 1e Internationaal Linguisten Congres in Den Haag, 1928, (als ik het goed heb gehoord): „Een Indo-Europeaan, dat is een baas die er op gesteld is een baas te blijven en te regeeren over zichzelve (en over de anderen)."
} 
- Deze inzichten in het wezen van den Warau vinden nu een zekere bevestiging en aanvulling in zijn opvattingen van de wereld, en het eigenaardig waarnemingsvermogen waarop dit berust. Voor zoover wij weten, komt dit in hoofdzaak overeen met hetgeen bij de Arawakken en Karaïben is aangetroffen, en bij deze is er een natuurlijke aanleg tot gewaarworden van bovenzinnelijke dingen. Gemakkelijk kan die aanleg zoo opgekweekt worden, dat men samenhangende waarnemingen krijgt van wezens, die zich o.a. kenbaar maken als het innerlijk van de natuur ${ }^{1}$ ).

Dat beleven vindt bij de inwijding plaats in een trancetoestand, dus wanneer de zelfbewuste wilspersoonlijkheid is uitgeschakeld, en dat wijst er duidelijk op dat dit soort helderzien (en -hooren) eenvoudig is het gewaarworden in de menschen-natuur van de beginselen die in de natuur zijn en werken ${ }^{2}$ ).

Ook deze dingen komen, in verschillende nuancen, algemeen voor bij primitieve volken en volken der oudheid.

Ongetwijfeld zijn vele mededeelingen hierover een napraten van wat door anderen is medegedeeld, rijkelijk aangevuld uit fantasie, waarbij ook politiek of eigenbelang wel eens in het spel zal komen. Maar mij dunkt, dat er geen sprake van kan zijn dat het uitsluitend verzinsels zouden wezen, of kinderlijke pogingen tot verklaring van natuurverschijnselen.

Hoezeer het den Warau hierbij ernst is, blijkt uit het woord voor medicijnman (ingewijde priester-dokter): $w i$ sidatu $=w i$ verwijderen ( $a$-) sida $\mathrm{kwaad}-t u$ persoon die doet of is.

1) Karaïben die dit zelve hebben doorgemaakt, hebben hun belevingen medegedeeld aan A. Ph. Penard, die dit nauwkeurig heeft beschreven in zijn opstel Het pujai-geheim der Surinaamsche Caraïben, Bijdr. T. L. en V. v. Ned. Indië, deel 84 , 's Gravenhage 1928; uitvoerig besproken en nader toegelicht in den W.-I. Gids, $11 \mathrm{e}$ jaargang, 's Gravenhage 1929.

2) Bij het scbrijven van mijn werk over het Arawaksch (The Arawak language of Guiana, Verh. Kon. Ak. v. Wet. afd. lett. nw. r. XXVIII no. 2, Amsterdam 1928) was het mij nog niet duidelijk dat de eigenaardige taalverschijnselen en de medicijnwetenschap van deze Indianen, loten van eenzelfden stam moeten zijn. 
Van de levendigheid der waarnemingen getuigen de volgende woorden:

$H e b u=$ natuurgeest; deze geesten werken in de natuur en toonen zich ook rechtstreeks in verschillendegedaanten; de mensch kan erdoor bezeten worden, wat zich dan openbaart als ziekte. Het woord drukt vrij zeker uit: he bleek $b u$ levende verschijning.

$(A-) k a h e b u$, dat vermoedelijk uitdrukt: $k a$ vasthoudend, kracht of levendig, hebu als voren. Het woord werd mij opgegeven als beteekenende menschelijke ziel, en ziel van een afgestorvene, en bovendien voor een schaduw en het beeld in een spiegel. De menschelijke ziel wordt overigens meestal $(a-)$ mehokohi genoemd; P. de Olea geeft dit woord ook op voor schaduw en portret.

Een dergelijke overeenstemming tusschen de woorden voor ziel, schaduw en afbeelding, is ook aangetroffen bij de Arawakken en Karaïben, en de opvatting dat schaduw en afbeelding met het leven van den persoon zelve verbonden zijn, komt ook voor bij natuurvolken in andere werelddeelen.

Nog sterker: Nimuendajú, een wetenschappelijk onderzoeker die door Indianen in Brazilië tot lid van hun stam was aangenomen, vertelt hoe de dierlijke ziel van een man die gedood was geworden, als een kwade demon de menschen verontrustte. Men stelde zich in hinderlaag om den demon te vernietigen. De aanvoerder werd gewaar dat de demon naderde, en toen deze dicht genoeg bij was wees hij aan $\mathrm{N}$. in welke richting hij hem waarnam. $\mathrm{N}$. schoot in die richting, doch het schot was volgens de Indianen mis; het tweede schot had het gewenschte resultaat. $\left.{ }^{1}\right)$.

- De moeilijkheid om het kaf van het koren te scheiden, ligt daarin, dat wijzelve dit soort waarnemingsvermogen niet bezitten, en dus verstandelijk moeten beoordeelen wat ligt in een andere zielelaag dan die van ons denkend verstand.

1) C. Nimuendajú-Unkel, Die Sagen von der Erschaffung und Vernichtung der Welt als Grundlage der Religion der Apapocúva-Guaraní. Zeitschrift für Ethnologie, Berlin 1914. 
Want er is een bepaald verschil tusschen ons waarnemen en logisch denken, en het beleven van den Indiaan. Dat blijkt o.m. daaruit, dat ons denken zich eerst recht thuisvoelt in alles wat vast en onveranderlijk is: ruimtelijke verhoudingen, materie, natuurwetten. En daarin verschilt het zeer van de Indiaansche opvattingen. De Indiaan let minder op het vaste ding als zoodanig; dit is hem voornamelijk drager van eigenschappen, en die eigenschappen hebben een karakter dat wij magisch noemen. Of de zichtbare verschijning is hem de uitdrukkingsvorm van een wezen, dat zich kan metamorfoseeren in een andere verschijning.

In overeenstemming hiermede heeft de Warau voor water of vloeist of een oorspronkelijk woord, $h o$, doch eenige woorden voor het vaste doelen klaarblijkelijk slechts op bijzondere verschijningsvormen van ho, n.l. hoyo $=$ rots, hota $=$ aarde, horo $=$ bast of schil.

Het reeds genoemde ha duidt aan ,er is"; ho verschilt hiervan slechts door de o die meer het stille en gevoelsrijke uitdrukt. Doch in het Arawaksch, waar de klinkers ongeveer dezelfde waarden hebben als in het Warau, duiden de $o$ en $u$ ook aan de natuur, het vrouwelijke en het vochtig-vloeibare ${ }^{\mathbf{1}}$ ). - De $o$-klank ontstaat als de spreker zijn mondholte maakt tot een groote ruimte, en het valt dus niet te verwonderen, dat de $o$ in het Arawaksch wordt gebezigd in woorden als oolai, gat, loko, roko, in. Dat vindt men ook in Warau-woorden: koho, gat, noko, ontvangend, opneem-plaats (in tegenstelling met $h i=$ punt, doorn, ei, en $h a=$ er is, nest, hangmat). - En vgl. nu nog hoko, het nieuwe daglicht (ho-vermogen), ho-duru$y a$, donder (ho-dondergeluid-gebeuren), ho-bari-bari-ya, bliksem, (ho-schitteren-gebeuren), ho-a-rao-tu, volgens de Olea een naam voor den medicijnman (ho-heer).

Misschien duidt ho eigenlijk aan: het levende wezen der wereld in dat aspect hetwelk zich vooral toont in het vloeibare.

1) The Arawak language of Guiana, $\S \S 119,125,190,191$. Het Warau heeft geen afzonderlijke grammaticale vormen voor verschillende geslachten. 
Dit doet denken aan de philosophiën der oudheid: het panta rei (alles stroomt) van Heraclitus, en de opvattingen van het oerelement: het onbegrensde, vuur, lucht of water, die door verdichting en verdunning in elkaar overgaan, en waarmede ook de substantie der ziel wel wordt vergeleken. Een onderscheiding die misschien van denzelfden aard is lezen wij in Genesis I: eerst is er geest, dan wordt licht geschapen, vervolgens water en ten slotte aarde, waarna het leven ontstaat; daarna worden de hemellichten geschapen, de luchtdieren, de waterdieren, en het laatst de aardedieren.

Zulke graden van ijlheid en bewegelijkheid, zoowel in de buitenwereld als in de ziel, worden echter in het Warau en andere talen mede-uitgedrukt door de klinkers $i-e-a-o$, en wellicht niet geheel toevallig, in de volgende woorden:

$h i$ (in samenstellingen) $=$ het heete: hokohi $=$ de zon als warmtegever (hoko $=$ daglicht), ihidy $a=$ warm

$\begin{array}{ll} & (-d y a=\text { sterk gevesti } \\ \text { behe } & =\text { licht, schijnsel; }\end{array}$

ha (in samenstellingen) $=$ het luchtachtige: ahaka $=$ wind, wolk, $a h a-n-=$ rui-

ho ken, $a h a=$ tabak; $=$ water.

- En de mensch? - Het lichaam is teho, vermoedelijk tai sterk ho vloeist of (materie). Bloed is hoti, vermoedelijk $h o$ vloeistof $t i$ takjes of fijne sterkte. De ziel is mehokohi, misschien hokohi zon (in) me het binnenste of de borst.

De gezamenlijke jonge mannen, ondergeschikt aan een hoofd, zijn nebo, vermoedelijk ne nederig bo verschijning; één man is nebora, vermoedelijk nebo het man-begrip $r a$ geconcentreerd in een punt; één ondergeschikte is nebora$t u ;-t u=$ persoon die is of doet. Nepoio, de naam van een Indianenstam die volgens oude berichten bij de monden der Orinoco en op Trinidad woonde, is wellicht het woord nebo. De vrouw is $t i d a$, misschien $t i$ deze kleine ida machtige of rijke - bij de Waraus heerscht het matriarchaat.

Volk of familie duidt men aan door $a$-rau, kennelijk 
hetzelfde als $d a u$, boom (de $d$ wordt dikwijls $r$ na een klinker), en de Waraus zijn het $W a$-volk. $W a$ drukt ongeveer uit: $w$ de eigenschap van onvatbaar, wijkend, of etherisch, geestelijk (die zich toont in) $a$ de gewone wereld, en het is mogelijk dat wa-rau zooiets beduidt als hemelingen, ook al omdat een mythe ${ }^{\mathbf{1}}$ ) vertelt hoe oorspronkelijk de Waraus, die toen nog allen jong waren, in den hemel woonden. Een jonge Warau, Okonorote (vermoedelijk hokona dageraad a-rao-tu heer) ontdekte een gat en zag daardoor de aarde; hij was de eerste die afdaalde. De laatste die afdaalde was een dikke vrouw, die in het gat bleef steken, en dientengevolge kan men thans niet meer door het uitspansel zien. De vrouw is Okonakura $=$ de morgenster (hokona dageraad kura ster). - In deze mythe (niet in de klanken der namen) verschijnt weder de tegenstelling: vlug en dun-mannelijk (actief), en stil en vochtig-zwellend-vrouwelijk (passief-receptief), die zoo schoon is geschilderd, zoo het heet door den grooten Lau Tze zelve, in het oud-Chineesche Boek der Puurheid ${ }^{2}$ ).

Zoo komen wij terug bij ons uitgangspunt: het volk der Waraus, welks hoofdmassa woont in en om de delta van de machtige rivier die de Arawakken noemen Wulinuku, de Europeanen Orinoco of Orenoque, terwijl Wyatt (reis van Dudley, 1594) vermeldt werinóca, the entring in of the ryver. Noko beduidt in het Warau ontvangend, opnemende plaats (bijv. in ha-noko, = huis, = verblijfplaats of hangmatplaats), en voorloopig mogen wij wel aannemen dat Orinoco een Warau-woord is, met de beteekenis van "eigen verblijf" (ori = zichzelf) of „aanlegplaats" (were $=$ naderend, se-weri-noko $=$ aanlegplaats) of „roei-ingang” (wiri $=$ roeien).

\footnotetext{
1) Opgeteekend door Brett, ook vermeld door Roth en opgenomen in Indianermärchen aus Südamerika, herausgegeben von Th. Koch-Grünberg, Jena 1920.

2) Khing Kăng King. Sacred Books of the East, Vol. XL, Oxford 1891. Ned. vertaling achterin de Tau Teh Tsjing van Lau Tze door J. A. Blok, Amersfoort, 2e uitg. \pm 1918.
} 